\title{
COMMENTARY
}

\section{Nutrition Security and Sustainable Development Goals in Africa}

\author{
Ramadhani A. Noor ${ }^{1,3,4}$ and Wafaie W. Fawzi ${ }^{1,2,3}$ \\ Harvard T.H. School of Public Health, Departments of Nutrition ${ }^{1}$; Epidemiology ${ }^{2}$; Global Health and Population, USA ${ }^{3}$; Africa \\ Academy for Public Health (AAPH), Tanzania ${ }^{4}$.
}

*For Correspondence: Email: ramanoor@gmail.com; Phone: +255 787544200

Africa has the potential to feed the world. Agricultural production is up by $160 \%$ over the past 30 years $^{1}$. Eighteen sub-Saharan African countries have reached the Millennium Development Goals' first target of halving the proportion of people who are hungry ${ }^{2}$. And increasingly wider efforts are being launched across the continent aimed at improving food security. There is still a long way to go as Africa remains a net importer of food $^{3}$ with about $25 \%$ of the continent population still living in hunger ${ }^{2,4}$.

Malnutrition in all its forms continues to ravage Africa, with huge implications for mortality, health care costs, cognitive development and the economy ${ }^{5,6}$. Today, there are more stunted children in Africa than two decades ago ${ }^{4}$, and the risk of death before reaching age of five years is 15 times higher than among children in developed regions ${ }^{7}$. Almost a third of these deaths are caused by undernutrition and this contributes up to $8 \%$ loss of Africa's workforce ${ }^{4}$. Half of those surviving to working-age had suffered from stunting during childhood, losing an average of 1.2 years in school education ${ }^{4}$. In 2015, Africa's Gross Domestic Product (GDP) losses attributed to malnutrition rose to $11 \%$, and in some countries to $16.5 \%$, far greater than annual world GDP losses due to the global financial crisis of 20082010. No single 'disease' is a greater threat than malnutrition to the wellbeing and economic development in Africa.

The number of stunted children has been declining in all parts of the world, except in subSaharan Africa, where the numbers increased by about one third ${ }^{9}$. This is primarily driven by population growth and increasing urbanization ${ }^{10}$. Emerging global health threats like the recent Ebola epidemic, as well as climate change and conflicts, also play a part ${ }^{9-10}$. On the other hand, rapid nutrition transitioning with increasing intake of processed foods and unhealthy lifestyles contribute to increasing overweight and obesity trends especially in women and children ${ }^{11-14}$.

Achieving a resilient and nutrition-secure Africa is a necessary step for sustainable development. The big question is: how can Africa end all forms of malnutrition? At the end of 2015, African leaders joined the world in adopting the Sustainable Development Goals (SDGs), and committed to ending all forms of malnutrition by $2030^{15}$. The SDGs represent a unique opportunity and a framework to advance commitments on nutrition. At least 12 of the 17 SDGs contain indicators related to nutrition, placing nutrition as both an input to and outcome of the $\mathrm{SDGs}^{8}$. Taken together, they represent an increased realization that investments in nutrition support macroeconomic and societal growth.

Globally, every $\$ 1$ invested in proven nutrition programs offers benefits worth $\$ 16^{8}$; estimated returns may be higher in Africa. Focusing on nutrition can help achieve other SDGs and vice versa, especially for goals related to gender equality and health. However, the financing needed to achieve the 2030 commitments for sustainable development globally are extremely large, on the order of trillions of dollars annually ${ }^{16}$. Of particular concern is the lack of a financing mechanism, especially a mechanism to harness domestic resources in support of nutrition initiatives. New data from the Global Panel on Agriculture and Food Systems for Nutrition shows nutrition investment to achieve the World Health Assembly (WHA) Global Nutrition Target of reducing stunting by 2025 in just 15 African countries can result in $\$ 83$ billion in GDP growth ${ }^{17}$. Investments in line with the new framework will drive progress toward achieving four of the six WHA nutrition targets on alleviating stunting, wasting, and anemia, and increasing exclusive breastfeeding ${ }^{18}$. Achieving these targets would require increased 
investment of approximately US $\$ 1.8$ billion per year from donors and US $\$ 750$ million per year from African governments over the next decade ${ }^{17}$. The African Development Bank, through "The African Leaders for Nutrition", is engaging heads of state to make commitments for their countries. Political commitment is essential and a necessary catalyst towards 2025 Global Nutrition Targets in Africa.

To a great extent, we know which interventions work in improving nutrition in Africa $^{19}$. A number of nutrition-specific (for example, micronutrient supplementation, food fortification etc.) as well as nutrition-sensitive interventions (including those aimed at improving water, sanitation and hygiene (WASH) standards, increasing agriculture production, improving gender equality) have been documented ${ }^{20}$, perhaps the latter ones with relatively less clarity in the context of integrated interventions ${ }^{21}$. The strength of evidence on nutrition specific interventions makes their integration relatively easier ${ }^{20}$. A recent framework further identifies costs and proposes a subset of high-priority cost-effective interventions for rapid implementation ${ }^{17}$. This includes vitamin A supplementation, supportive breastfeeding policies, and food fortification. Notably, successful implementation of programs for selected high priority interventions has proven to be challenging. Vitamin A coverage in Africa, for example, has invariably turned out to be lower than reported ${ }^{22}$, while the exclusive breastfeeding rates have persistently remained below $50 \%{ }^{23}$. Likewise, data from large-scale food fortification programs show challenges in terms of access, consumption and compliance issues ${ }^{24}$.

To better understand how integrated packages to prevent malnutrition translate in the African context, multiple sectors need to work together ${ }^{25,26}$. These include sectors focusing on education, water and sanitation, agriculture, and health. Emerging evidence shows strong association between poor WASH standards and stunting ${ }^{20,27}$, and likewise a number of ongoing studies show links between agriculture, nutrition and health ${ }^{26,28,29}$. In many settings, however, nutrition-sensitive strategies implemented as part of development programs have largely remained vertically implemented ${ }^{30,31}$.
The greatest need for impact is within the households of smallholder farmers, who represent the majority of the African population and are most affected by malnutrition ${ }^{32}$. Hence, agriculture and nutrition integration must focus on promoting production of safe and diverse nutrient rich foods, coupled with increased consumption of these foods by women and children who are at greater risk of malnutrition. Evidence on the effectiveness of integrated packages is key for their scale up. And so is the knowledge on how to implement these packages. Capacity building of front line workers at community level, including health and agriculture extension workers is needed, as is enhanced competence in evidence translation to policy and programs, and greater skills in program management and monitoring and evaluation. Stronger ties are needed between academic and research institutions in Africa on one hand, and on the other hand policy makers and public and private providers across key sectors.

As the number of interventions that need to be included in integrated packages increase, implementation becomes even more challenging. Until recently the world lacked guidance on which program interventions to scale up, which were the most cost-effective and how they can be financed. This year the World Bank launched the first-ever investment framework for nutrition ${ }^{33}$ which provides the roadmap for accelerating progress against malnutrition. And countries are expected to implement evidence-based integrated interventions, packaged into minimum bundles possible, for effectiveness and impact in nutrition.

The count down for the SDGs has begun, and it is critical that mechanisms are instituted to support African countries as they gather the required data on appropriate metrics for regular progress reviews at the regional as well as the country level. The monitoring of the MDGs taught us that data are an indispensable element of the development agenda ${ }^{16}$. This remains true if we are to achieve nutrition security and overall targets set for the SDGs. We believe that many countries in Africa are on the right track. Strong consensus and commitment to achieve nutrition security exists among African countries and development partners. In 2014, the first ever agriculturenutrition integrated commitment was signed by the 
African heads of State, the Malabo Declaration ${ }^{34}$. This year, the United Nations declared the next 10 years to be a decade focused on nutrition ${ }^{35}$. Smart investments on the highest impact, most costeffective nutrition programs that can be scaled up are the way to go. Long-term strategic investments in nutrition will require political will, and context and data-driven decisions to catalyze Africa's commitment to end all forms of malnutrition by 2030, and achieve the SDGs.

\section{Conflict of Interest: None}

\section{References}

1. Plaizier, W. How Africa can feed the world _ World Economic Forum. at https://www.weforum.org/ agenda/2016/01/how-africa-can-feed-the-world/.

2. United Nations. The Millennium Development Goals Report. United Nations 72 (2015). doi:978-92-1101320-7.

3. Rakotoarisoa, M. A., Iafrate, M. \& Paschali, M. Why has Africa become a net food importer? Trade and Market Division, FAO (2012).

4. Abdridge report, A. U. The Cost of Hunger in Africa. WFP Summ. Rep. (2013). at http://www.costo fhungerafrica .com/download-reports/.

5. The Global Nutrution Report 2016: From Promise to Impact, Ending Malnutrition by 2030. at http:// ebrary.ifpri.org/utils/getfile/collection/p 15738coll2/id/130354/filename/130565.pdf.

6. Black, R. E. et al. Maternal and child undernutrition and overweight in low-income and middle-income countries. Lancet 382, 427-451 (2013).

7. Vakili, R., Moghadam, Z. E., Khademi, G. \& Vakili, S. Child mortality at different world regions: A comparison review. 3, 809-816.

8. The Global Nutrition Report 2016.

9. United Nations. Assessing progress in Africa toward the Millennium Development Goals. United Nations Economic Commission for Africa doi:accessed 26 July 2015.

10. Africa Progress Panel. Global African Realities : Building a sustainable Future for All. (2014). at http://app-cdn.acwupload.co.uk/wp-content/uploads /2015/09/APP_ExectuvieSummary_WEB.pdf.

11. Popkin, B. M., Adair, L. S. \& Ng, S. W. NOW AND THEN: The Global Nutrition Transition: The Pandemic of Obesity in Developing Countries. Nutr Rev 70, 3-21 (2013).

12. Cloete, K. African processed food demand to increase. Engeneering News at http://www.engineeringnews .co.za /article /african-processed-food-demand-toincrease-2014-06-18.

13. $\mathrm{Ng}, \mathrm{M}$. et al. Global, regional, and national prevalence of overweight and obesity in children and adults during 1980-2013: A systematic analysis for the
Global Burden of Disease Study 2013. Lancet 384, 766-781 (2014).

14. de Onis, M., Blössner, M. \& Borghi, E. Global prevalence and trends of overweight and obesity among preschool children. Am. J. Clin. Nutr. 92, 1257-1264 (2010).

15. United Nations. Transforming our world: The 2030 agenda for sustainable development. https:// sustainabledevelopment.un.org/content/documents/ 7891Transforming\%200ur\%20World. pdf (2015). doi:10.1007/s13398-014-0173-7.2.

16. Sachs, J. D. From millennium development goals to sustainable development goals. Lancet 379, 22062211 (2012).

17. Global Panel on Agriculture and Food Systems for Nutrition. How can Agriculture and Food System Policies Improve Nutrition? Technical Brief (2014).

18. Haddad, L., Zaidi, S. \& Gazdar, H. Investing in Nutrition. (2013).

19. Bhutta, Z. A. et al. Evidence-based interventions for improvement of maternal and child nutrition: What can be done and at what cost? Lancet 382, 452-477 (2013).

20. Ruel, M. T. \& Alderman, H. Nutrition-sensitive interventions and programmes: How can they help to accelerate progress in improving maternal and child nutrition? Lancet 382, 536-551 (2013).

21. Mucha, N. Briefing Paper: Implementing NutritionSensitive Development: Reaching Consensus. (2012). doi:10.1186/s12302-014-0034-1.

22. Katcher, H., Blankenship, J. \& Nankap, M. Vitamin A Supplementation (VAS) Coverage Data in Africa Modernizing data collection to inform distribution strategies. SIGHT LIFE 28, 103-108 (2014).

23. Victora, C. G. et al. Breastfeeding in the 21 st century: Epidemiology, mechanisms, and lifelong effect. Lancet 387, 475-490 (2016).

24. Tanzania FACT Survey Report. (2016). at http://www.nbs.go.tz/nbs/takwimu/references/FAC TSURVEY2015/FACT Report2015.pdf.

25. WFP. Nutrition sensitive programming: What and Why? Why should we adopt a nutrition sensitive approach ? West Africa Nutr. Bull. \#1 1-6 (2014).

26. Canavan, C. R., Graybill, L., Fawzi, W. \& Kinabo, J. The SDGs Will Require Integrated Agriculture, Nutrition, and Health at the Community Level. Food Nutr. Bull. 37, 1-4 (2016).

27. Cumming, O. \& Cairncross, S. Can water, sanitation and hygiene help eliminate stunting? Current evidence and policy implications. Matern. Child Nutr. 12, 91-105 (2016).

28. Qaim, M. Globalisation of agrifood systems and sustainable nutrition. Proc. Nutr. Soc. 1-10 (2016). doi:10.1017/S0029665116000598.

29. Girard, A. W., Self, J. L., McAuliffe, C. \& Olude, O. The effects of household food production strategies on the health and nutrition outcomes of women and young children: A systematic review. Paediatr. Perinat. Epidemiol. 26, 205-222 (2012).

30. Fanzo, J. et al. Integration of nutrition into extension and 
advisory services: A synthesis of experiences, lessons, and recommendations. Food Nutr. Bull. 36, 120-137 (2015).

31. Kennedy, E. et al. Multisector Nutrition Program Governance and Implementation in Ethiopia: Opportunities and Challenges. Food Nutr. Bull. 36, 534-548 (2015).

32. African Smallholder Farmers Group(ASFG). Africa's Smallholder Farmers: Approaches that Work for Viable Livelihoods. (2010). at http://www. asfg.org.uk/downloads/final-asfg---africassmallholder-farmers.pdf.

33. World Bank. 2016. Investing in nutrition : the foundation for development - an investment framework to reach the global nutrition targets. Washington,
D.C. : World Bank Group. at <hhttp://documents. worldbank.org/curated/en/2016/04/26231191/ investing-nutrition-foundation-developmentinvestment-framework-reach-global-nutritiontargets>.

34. African Union Commission. Malabo Declaration on Accelerated Agricultural Growth and Transformation for Shared Prosperity and Improved Livelihoods. (2014)

35. United Nations General Assembly. United Nations Decade of Action on Nutrition (2016-2025). 1-10 (2016). at http://www.fao.org/fileadmin/templates/ cfs/Docs1516/OEWG_Nutrition/3rd_Meeting/CFS_ OEWG_Nutrition_2016_04_29_01UN_Decade_Ac tion_Nutrition.PDF. 